\title{
O PROCESSO DE RESILIÊNCIA DE MULHERES VÍTIMAS DE VIOLÊNCIA DOMÉSTICA: UMA ABORDAGEM QUALITATIVA*
}

Tatiane Herreira Trigueiro', Liliana Maria Labronici², Miriam Aparecida Barbosa Merighi ${ }^{3}$, Maria Lúcia Raimondo ${ }^{4}$

${ }^{1}$ Enfermeira. Mestre em Enfermagem. Universidade Positivo. Curitiba-PR-Brasil.

Enfermeira. Doutora em Enfermagem. Universidade Federal do Paraná. Curitiba-PR-Brasil.

${ }^{3}$ Enfermeira. Doutora em Enfermagem. Universidade de São Paulo. São Paulo-SP-Brasil.

${ }^{4}$ Enfermeira. Mestre em Enfermagem. Universidade Estadual do Centro-Oeste do Paraná. Curitiba-PR-Brasil.

RESUMO: Pesquisa descritiva, qualitativa, realizada em serviço de acolhimento institucional, em Curitiba/Paraná, com 08 mulheres vítimas de violência doméstica. Os objetivos foram identificar o percurso da resiliência nas mulheres e conhecer os fatores que predispõem a resiliência. A coleta de dados ocorreu de novembro de 2010 a fevereiro de 2011, mediante entrevista aberta gravada e transcrita. Os discursos, analisados pela análise de conteúdo temática, revelaram o tema: A força do amor materno interrompendo o ciclo da violência doméstica e possibilitando o processo de resiliência. Evidenciou-se que o início do processo de resiliência ocorreu quando os filhos passaram a ser vítimas da violência e a permanência no serviço de acolhimento gerou perspectivas para a superação do vivido e possibilidades de um futuro melhor. As experiências das mulheres e dos fatores de resiliência oferecem subsídios à Enfermagem, possibilitando a realização de ações de enfrentamento e cuidado conforme as vivências das mesmas. DESCRITORES: Enfermagem; Saúde da mulher; Pesquisa qualitativa; Violência contra a mulher.

\section{THE PROCESS OF RESILIENCE IN WOMEN WHO ARE VICTIMS OF DOMESTIC VIOLENCE: A QUALITATIVE APPROACH}

\begin{abstract}
This is descriptive, qualitative research undertaken in a municipal domestic violence shelter service, in Curitiba, in the Brazilian state of Paraná, with eight women who were victims of domestic violence. The objectives were to identify the trajectory of the women's resilience and to investigate the factors which predispose to resilience. Data collection occurred between November 2010 and February 2011, through open interviews which were recorded and transcribed. The discourses, analyzed using thematic content analysis, revealed the theme: The strength of maternal love interrupting the cycle of domestic violence and making the process of resilience possible. It was evidenced that the process of resilience was initiated when the children came to be victims of violence and that staying in the shelter created the possibility of overcoming what had been experienced and possibilities for a better future. The women's experiences, and the factors of resilience, offer support for Nursing, making it possible to undertake nursing actions and care in accordance with the women's experiences. DESCRIPTORS: Nursing; Women's Health; Qualitative Research; Violence against Women.
\end{abstract}

\section{EL PROCESO DE RESILIENCIA DE MUJERES VÍCTIMAS DE VIOLENCIA DOMÉSTICA: UN ABORDAJE CUALITATIVO}

RESUMEN: Investigación descriptiva, cualitativa, realizada en servicio de acogimiento institucional, en Curitiba/ Paraná, con 08 mujeres víctimas de violencia doméstica. Los objetivos fueron identificar el percurso de la resiliencia en las mujeres y conocer los factores que predisponen la resiliencia. Los datos fueron obtenidos de noviembre de 2010 a febrero de 2011, por medio de entrevista abierta grabada y transcripta. Los discursos, analizados por el análisis de contenido temático, revelaron el tema: La fuerza del amor materno interrompiendo el ciclo de la violencia doméstica y posibilitando el proceso de resiliencia. Se evidenció que el inicio del proceso de resiliencia ocurrió cuando los hijos pasaron a ser víctimas de la violencia y la permanencia en el servicio de acogimiento generó perspectivas para la superación del vivido y posibilidades de un futuro mejor. Las experiencias de las mujeres y de los factores de resiliencia ofrecen subsidios a la Enfermería, posibilitando la realización de acciones de afrontamiento y cuidado de acuerdo a las vivencias de estas.

DESCRIPTORES: Enfermería; Salud de la mujer; Investigación cualitativa; Violencia contra la mujer.

*Artigo extraído de Dissertação de Mestrado intitulada: O processo de resiliência de mulheres vítimas de violência doméstica: contribuições para o cuidar em enfermagem, desenvolvida na Universidade Federal do Paraná, 2011. 


\section{INTRODUÇÃO}

As adversidades fazem parte da vida do ser humano e, entre elas, destaca-se a violência doméstica contra as mulheres, porquanto é um evento traumático que afeta as suas múltiplas dimensões. Nesse sentido, diante de um trauma, o indivíduo possui duas alternativas: deixarse abater pelo sofrimento ou buscar formas e elementos que propiciem o enfrentamento, sendo este o início do processo de resiliência.

A resiliência pode ser entendida como uma possibilidade de recuperação e superação diante da adversidade, com o objetivo de fortalecer, recuperar e tornar mais forte emocionalmente o indivíduo ${ }^{(1)}$. Frente a um trauma alguns indivíduos paralisam e não conseguem sair do problema, o que pode levá-los a mergulhar em patologias graves que alteram sua saúde física e mental. Todavia, outros conseguem enfrentar as adversidades e adaptar-se positivamente aos traumas vividos, apresentando um comportamento de superação e de retomada à vida(2), fato que evidencia a capacidade de resiliência.

Resiliência é um conceito que vai além da invulnerabilidade humana aos eventos estressantes ou de sua capacidade de recuperação diante das adversidades. Trata-se de um processo dinâmico que qualquer indivíduo pode dar início em meio a uma variedade de condições biológicas, genéticas e ambientais, apesar da adversidade presente $^{(3)}$.

A utilização do conceito da resiliência é recente na área da saúde, entretanto, o neuropsiquiatra francês Boris Cyrulnik, em virtude de sua própria história de superação de vida nos campos de concentração nazistas, dedicou sua vida a estudos voltados ao desenvolvimento desse conceito, tornando-se um importante estudioso no tema ${ }^{(4)}$. A capacidade de superação entre pessoas, frente às adversidades da vida, e foco de investigações de estudiosos e pesquisadores em diversas áreas do conhecimento na atualidade(2).

Em síntese, o processo de mobilização interna, que desencadeia um movimento de rupturas e de abertura em direção ao outro com o intuito de se ajudar e ser ajudado, de transcender a experiência vivida e encontrar um novo sentido para a existência, denomina-se resiliência ${ }^{(5)}$.

Na Enfermagem, a utilização do conceito da resiliência é recente, com seu início a partir da década de 1990, na qual as publicações estavam direcionadas para crianças e adolescentes. Assim, ao perscrutar a literatura relacionada à temática da resiliência, evidenciou-se a escassez de estudos voltados às mulheres vítimas de violência doméstica, na área da saúde.

Destarte, a realização desta pesquisa se justifica, pois uma das profissões da área de saúde mais comprometida com a promoção, prevenção e recuperação da saúde dos indivíduos é a Enfermagem. Os profissionais podem contribuir para a identificação e prevenção dos fatores de risco que podem gerar a violência, na tentativa de proteger as vítimas deste agravo, que causa danos à saúde. Diante disso, é fundamental que estejam preparados para reconhecer o processo de resiliência de forma a estimular seu desenvolvimento, visto que este pode ser um dos seus instrumentos de trabalho.

Deste modo, na medida em que se busca a experiência, por meio do vivido das mulheres vítimas de violência doméstica, há ações de cuidado para a assistência a este tipo de clientela, além do que a enfermeira pode incitar o processo de resiliência, e desta forma, ser tutora ${ }^{(5)}$.

Frente às considerações mencionadas, surgiu a pergunta que norteou o desenvolvimento dessa pesquisa: As mulheres vítimas de violência doméstica estão em processo de resiliência? Diante da necessidade de responder essa inquietação, os objetivos foram: Identificar o processo de resiliência de mulheres vítimas de violência doméstica, residentes em um serviço de acolhimento institucional e conhecer os fatores que predispõem a esta resiliência.

\section{MÉTODO}

Trata-se de pesquisa descritiva com abordagem qualitativa, desenvolvida em um serviço de acolhimento institucional da Fundação de Ação Social da Prefeitura de Curitiba-PR-Brasil. $\mathrm{O}$ encaminhamento para este serviço ocorre por meio dos Núcleos regionais, Centrais de atendimento social, Delegacia da Mulher, Conselhos Tutelares, Vara da família e Conselho Municipal da Condição Feminina e Unidades de Saúde. Entre os anos de 1993 a 2007, a média de atendimento anual naquele serviço foi de 63 mulheres ${ }^{(6)}$. 
Definiu-se como critério de inclusão mulheres acima de 18 anos que estavam residindo no serviço de acolhimento institucional entre novembro de 2010 a fevereiro de 2011. Participaram da pesquisa oito mulheres vítimas de violência doméstica, mediante entrevista gravada. Não houve necessidade de realizar mais entrevistas, porque os conteúdos dos discursos responderam a inquietação das pesquisadoras e os objetivos do estudo.

A aproximação com as participantes da pesquisa deu-se por meio de reunião com os profissionais deste serviço e com as mulheres, na qual a pesquisadora se apresentava, explicitava a pesquisa, e após manifestação do interesse em participar, a oficialização ocorreu mediante a assinatura do Termo de Consentimento Livre e Esclarecido.

A obtenção dos depoimentos ocorreu por meio da seguinte questão norteadora: Conte-me sobre o dia-a-dia com seu companheiro antes de vir para este serviço. As entrevistas foram realizadas em espaço privado, o que contribuiu para que as mulheres pudessem relatar o ocorrido sem se sentirem constrangidas ou serem interrompidas. Posteriormente, os depoimentos foram transcritos e analisados por meio da Análise de Conteúdo do tipo Temática ${ }^{(7)}$, que possui quatro etapas: organização da análise, codificação, categorização e inferência.

Neste tipo de análise o pesquisador realiza leitura exaustiva dos discursos, a fim de se familiarizar com a experiência vivida; posteriormente, recorta segmentos do conteúdo que expressam em seu sentido uma representação significativa de acordo com o objetivo do estudo, denominada de unidades de registro. Após este recorte, as unidades são agregadas e organizadas, de forma a possibilitar a interpretação e, assim, encontrar em sua essência, o sentido da fala, que permite elaborar os temas da análise ${ }^{(7)}$. A discussão dos resultados foi embasada em referências relacionadas à temática em questão.

No que diz respeito aos aspectos éticos o projeto foi aprovado pelo Departamento Jurídico da Fundação de Ação Social (protocolo 01112807/2010), e pelo Comitê de Ética em Pesquisa do Setor de Ciências da Saúde da Universidade Federal do Paraná (Registro CEP/SD:943.068.10.06 - C.A.A.E.:0042.0.091.000-10). Em consideração à Resolução sobre ética em pesquisa, para manter o anonimato das mulheres participantes da pesquisa, as entrevistadas foram identificadas com a letra $M$, seguida de algarismo arábico em ordem crescente de realização da entrevista.

\section{RESULTADOS}

Ao conhecer o perfil das oito mulheres participantes deste estudo, verificou-se a faixa etária compreendida entre 28 a 39 anos. Antes de chegar ao serviço de acolhimento institucional, para mulheres vítimas de violência doméstica, todas eram dependentes financeiramente do companheiro e apenas uma trabalhava como auxiliar de limpeza. O número de filhos variou de um a seis, com uma média de três filhos, e no momento da entrevista três estavam gestantes. A média do tempo de permanência com o companheiro foi de 8,12 anos, e o tempo de permanência no Serviço, variou de seis dias a dez meses, sendo a média de 68,62 dias, e uma delas estava no local pela segunda vez.

As experiências das mulheres vítimas de violência doméstica convergiram para a seguinte temática: A força do amor materno interrompendo o ciclo da violência doméstica e possibilitando o processo de resiliência.

Nesta pesquisa, as mulheres participantes do estudo sofreram violência psicológica, física e patrimonial, entretanto, o início do processo de resiliência, ou seja, o que as fez romper com o ciclo da violência sofrida, ocorreu a partir do momento em que seus filhos também passaram a ser vítimas da violência, conforme evidenciado no recorte da fala abaixo:

Dessa última vez ele bateu nela [filha], e quando eu vi, ela estava com o nariz sangrando [...]. Eu me desesperei, peguei ela, pulei a janela do quarto e corri para a rua. Isso eram três horas da manhã, $e$ liguei para polícia. Fiz pela minha filha, porque eu não aceito que ele bata nela; ela é tudo para mim. Então foi por ela que eu tive força. (M8)

A violência praticada contra os filhos fez com que essas mulheres também despertassem para o fato de que o convívio com a violência doméstica pode afetar a integridade física e psicológica de todos os membros da família. A preocupação das mães em afastar a família do cenário, no qual a violência se fazia presente, pode ser constatada nos fragmentos de discursos apresentados a seguir: 
Danem-se meus sentimentos. Em primeiro lugar vem a integridade mental dos meus filhos. Como é que duas crianças vão crescer em um ambiente como esse, em que um dia o pai é a melhor pessoa do mundo, e no dia seguinte está quebrando a casa? Como é que vão crescer? Não, meus filhos não merecem isso! Foi nisso que eu pensei na hora. Só pensei nos dois. (M4)

Eu fui para a FAS [Fundação de Ação Social] para procurar uma coisa melhor para mim e as crianças, porque eles precisam de uma coisa melhor, não de briga em casa, como estava. Porque eles não podem se criar vendo aquilo, principalmente ele [filho] porque ele vai querer fazer a mesmo que o pai faz. (M2)

O desejo de proteger os filhos da violência pode ser percebido antes mesmo de seu nascimento. A aspiração de dar continuidade a uma gestação, renegada pelo companheiro agressor, foi outro motivo que também ajudou no rompimento do ciclo da violência, e pode ser percebido no discurso abaixo:

Eu vim parar aqui [Serviço de Acolhimento Institucional] porque ele [o marido] descobriu que eu estava grávida, e meu marido queria que eu tirasse o nenê. Ele começou a brigar muito. Quando eu resolvi ter um filho dele, ele me diz que não quer mais. Agora deixa ele [bebê] aqui, quando estiver pronto ele vai nascer. (M7)

Para enfrentar o vivido, as mulheres participantes da pesquisa necessitaram abandonar o ambiente permeado pela violência, e assim, procuraram ajuda e foram abrigadas, juntamente com seus filhos, no serviço de acolhimento institucional. A possibilidade de permanecer nesse local e em companhia dos filhos foi crucial para dar continuidade ao processo de resiliência, pois permitiu desenvolver alguns traços de superação da experiência, o que pode ser constatado nos fragmentos dos discursos a seguir:

O meu pensamento tá em seguir em frente para eu trabalhar e dar as coisas para eles [filhos], porque estou pensando é nas duas vidas que eu tenho [...] eu tenho que seguir em frente porque eles vão precisar de estudo, carinho, e eu vou ter que estar ao lado deles para o que der e vier [...] vou ter que lutar por eles. (M2)

Os meus filhos, todo dia eu olho para eles e vejo que precisam de mim. Eles são tudo para mim [...]. Eu acredito que com todo esse sofrimento ainda vai vir a alegria. Quem sabe amanhã nós vamos rir dessa vida que nós tivemos, e vamos falar "nossa quanta coisa nós passamos juntos". (M5)

\section{DISCUSSÃO}

O conceito de resiliência apresenta a possibilidade de entender o estresse, como oportunidade de crescimento e fortalecimento pessoal, entretanto, faz-se necessário encontrar um equilíbrio entre proteger as crianças de riscos e proporcionar as oportunidades e o desenvolvimento necessários para a promoção da saúde ${ }^{(8)}$. Deste modo, diante do sentimento materno de proteção e preservação da vida, bem como, da necessidade de prover um ambiente familiar saudável para o desenvolvimento dos filhos, as mulheres sentiram a necessidade de enfrentar e romper com o ciclo da violência.

As crianças, frente a sua necessidade de explorar o mundo e por seu temperamento e vitalidade, frequentemente tendem a ficar expostas à agressividade dos pais, e a tornar-se uma válvula de escape para as tensões e conflitos familiares ${ }^{(9)}$. Todavia, importante se faz destacar que interações familiares conflituosas, permeadas por estresse e perturbações, vivenciadas na infância podem influenciar o desenvolvimento mental e intelectual adequado das crianças ${ }^{(10)}$. Assim, é relevante a preocupação das mães em afastar os filhos do contexto da violência, conforme foi evidenciado no estudo em tela.

Estudo evidencia que acontecimentos negativos vivenciados na infância, como no caso da violência, podem afetar a estrutura psíquica do ser quando este se torna adulto. Desta forma, o sofrimento psíquico resultante da violência sofrida quando criança, poderá dificultar o crescimento e desenvolvimento saudável, tornando-a um adulto vulnerável ${ }^{(11)}$. A família apresenta-se como um dos principais responsáveis pelo adequado desenvolvimento biopsicossocial da criança. Nesta perspectiva, sentindo-se responsáveis 
pelo adequado desenvolvimento de seus filhos, as mães vítimas de violência decidiram afastálos deste contexto, rompendo com a relação e distanciando-se do agressor.

Dados de um estudo desenvolvido com usuárias de serviços de saúde concluíram que a violência vivenciada por filhos contra suas mães no ambiente doméstico, pode ser um fator de risco para que a violência permeie as relações afetivas na vida adulta ${ }^{(12)}$. Desta forma, as marcas deixadas pela violência podem afetar profundamente o curso da experiência individual ao longo da vida. A criança que vivencia a violência doméstica pode desenvolver sentimentos negativos de vida $^{(13)}$.

Outra manifestação de proteção aos filhos ocorreu ainda durante a gestação, quando frente a não aceitação da gestação por parte do companheiro e a solicitação de sua interrupção, a mulher optou em dar continuidade à gravidez, passando a sofrer violências constantes. Frente ao risco de não ver concretizado seu desejo de ser mãe, em razão da violência, a mulher decidiu enfrentar e procurou o serviço de acolhimento para obter a proteção e tranquilidade necessárias para consecução de uma gestação saudável.

Estudo realizado no Canadá com mulheres que sofreram violência psicológica, física e sexual pelo parceiro íntimo durante a gestação, constatou a sua associação com a depressão pós-parto ${ }^{(14)}$, deste modo a violência contra a mulher grávida pode repercutir em consequências severas agudas e a longo prazo. Assim, o desejo de proteger os filhos, os sonhos, a vontade de proporcionar uma vida melhor e os planos para o futuro junto a eles são fatores para as mulheres traçarem novos caminhos e perspectivas de vida, livres do medo e da insegurança.

Um dos fatores externos de suporte nesta pesquisa foi o serviço de acolhimento institucional, porquanto possibilitou o desenvolvimento e a continuidade do processo de resiliência nas mulheres entrevistadas. Assim, a inserção da enfermeira nos serviços de acolhimento institucional é fundamental, visto a possibilidade de realizar atendimento individual, mediante consulta de enfermagem a fim de desenvolver ações técnicas de cuidado relacionadas aos aspectos fisiológicos, bem como ações que envolvem a subjetividade e cultura das mulheres, identificando fatores de risco, prevenindo doenças, promovendo a saúde e auxiliando para melhorar a qualidade de vida(15).

O processo de cuidado às mulheres em situação de violência não ocorrerá isoladamente, mas sim, por meio de intencionalidade, interação, disponibilidade e confiança entre enfermeira e paciente. Desta maneira, requer profissionais capacitados e sensíveis, a fim de extrapolar as ações técnicas de cuidado ${ }^{(16)}$.

A enfermeira ao prestar cuidado direcionado para a multidimensionalidade da mulher vítima de violência doméstica poderá incitar o desenvolvimento do processo de resiliência, mediante postura de acolhimento, flexibilidade, abertura, escuta e diálogo, e isso possibilitará conhecê-la, a fim de captar a dor íntima, aquela que não se trata com curativos e medicamentos, mas sim por meio de uma inter-relação ética, solidária e humanizada.

Ao atuar no enfrentamento da violência doméstica, a enfermeira poderá também, dentre outras ações de cuidado, ser tutora da resiliência mediante o estabelecimento de um acolhimento que perceba a mulher em sua totalidade, como um ser no mundo que diante da dominação, a exploração e o sofrimento, requer auxílio para a superação ${ }^{(5)}$.

A compreensão dos discursos das mulheres entrevistadas retrata uma trajetória de lutas, abdicações da família e do lar para possibilitar a proteção dos filhos, segurança, harmonia, uma vida digna e sem violência. Isso proporciona a superação, a continuidade do processo de resiliência das participantes, pois embora o distanciamento exija rupturas com o outro, com um passado marcado pela dor e sofrimento, por outro lado, possibilita garantir a integralidade física e psicológica de si e dos filhos, o estabelecimento de um vínculo seguro e uma vida mais saudável. Quando as redes de apoio estão presentes e envolvem o indivíduo traumatizado é possível estimular ou reforçar a resiliência.

\section{CONSIDERAÇÕES FINAIS}

A realização desta pesquisa permitiu compreender que as mulheres vítimas de violência doméstica, residentes em um serviço de acolhimento institucional, encontravam-se em processo de resiliência. $\mathrm{O}$ enfrentamento teve início quando a violência doméstica deixou de ser somente direcionada a elas e passou a atingir 
também os filhos, fazendo com que fossem em busca de ajuda.

A possibilidade de permanecer junto aos filhos nesse serviço, fez com que apresentassem perspectivas de superação do vivido, na medida em que relataram planos para o futuro e o desejo de proporcionar melhor qualidade de vida para toda a família.

Acreditamos que o conhecimento produzido nesta pesquisa poderá contribuir não apenas para a ampliação do conhecimento relacionado aos temas resiliência e violência doméstica contra a mulher, mas para a assistência de enfermagem direcionada a esta clientela. Há inúmeros indicativos para que as ações de cuidados transcendam a dimensão física, para além do visível, em direção à subjetividade, local onde ficam armazenadas as experiências vividas por um corpo que sente e se relaciona com o mundo. Entretanto, as marcas provenientes do vivido têm influência no modo de viver e/ou adoecer.

Além disso, a utilização do conceito resiliência no ensino da enfermagem poderá fortalecer a prática de cuidados, que visem à prevenção, promoção e recuperação da saúde, e, consequentemente, proponham caminhos para que seja possível melhorar a qualidade de vida dessas mulheres. Possibilitarão também, reflexões no ensino, pesquisa e na assistência, que incluem o conhecimento do processo de resiliência inserido no cuidado a esta população.

Não obstante, a compreensão do processo de resiliência de mulheres vítimas de violência doméstica ficou limitada a uma população específica, o que impede que os achados sejam generalizados, vez que mostra a vivência específica de vítimas que residem em um mesmo local.

\section{REFERÊNCIAS}

1. Brandao JM, Mahfoud M, Gianordoli-Nascimento IF. A construção do conceito de resiliência em psicologia: discutindo as origens. Paidéia. [Internet] 2011;21(49). [acesso em 03 jul 2014]. Disponível: http://dx.doi. org/10.1590/S0103-863X2011000200014

2. Benetti IC, Crepaldi MA. Resiliência revisitada: uma abordagem reflexiva para principiantes no assunto. REID. [Internet] 2012;7(7). [acesso em 02 jul 2014]. Disponível: http://www.ujaen.es/revista/reid/revista/ n7/REID7art1.pdf
3. Cortés BGM, Cruz LP. Resiliencia: ¿Es posible medirla e influir en ella?. Salud Ment. [Internet] 2011;34(3). [acesso em 02 jul 2014]. Disponível: http://www.scielo. org.mx/pdf/sm/v34n3/v34n3a7.pdf

4. Universidade Federal do Rio Grande do Norte. Boris Cyrulnik em Natal. [Internet] 2009;2 [acesso em 25 jan 2014]. Disponível: https://docs.google.com/ document/d/1SII70HJ2qXmzg72C3phl3CsxgilJX4qVP q8wlOdG2uE/edit

5. Labronici LM. Resilience in women victims of domestic violence: a Phenomenological view. Texto Contexto Enferm. [Internet] 2012;21(3) [acesso em 02 jul 2014]. Disponível: http://dx.doi.org/10.1590/S010407072012000300018

6. Labronici LM, Ferraz MIR, Trigueiro TH, Fegadoli D. Profile of the violence commited against women assisted at Pousada de Maria lodging. Rev Esc Enferm USP. [Internet] 2010;44(1) [acesso em 25 jan 2014]: Disponível: http://dx.doi.org/10.1590/S008062342010000100018

7. Bardin L. Análise de conteúdo. $4^{\mathrm{a}}$ ed. Lisboa: Edições 70; 2009.

8. Franco V, Melo M, Apolonio A. Child's development problems and early intervention. Educ. rev. [Internet] 2012;(43) [acesso em 02 jul 2014]. Disponível: http:// dx.doi.org/10.1590/S0104-40602012000100005

9. Rocha PCX, Moraes C. Violência familiar contra a criança e perspectivas de intervenção do programa saúde da família: a experiência do PMF/Niterói (RJ, Brasil). Ciênc. saúde colet. [Internet] 2011;16(7) [acesso em 02 jul 2014]. Disponível: http://dx.doi.org/10.1590/ S1413-81232011000800028

10. Zerk DM, Mertin PG, Proeve M. Domestic violence and maternal reports of young children's functioning. J. Fam. Viol. [Internet] 2009;24(7) [acesso em 02 jul 2014]. Disponível: http://link.springer.com/ article/10.1007\%2Fs10896-009-9237-4\#page-1

11. Oliveira EN, Vasconcelos MC, Costa FBC, Eloia SC, Lopes MVO, Gubert FA. Abuso e Maus-tratos na Infância. Caracterização deste fenômeno em adolescentes do sexo feminino. In: Escola Superior de Enfermagem do Porto. Saúde e qualidade de vida: uma meta a atingir. Porto; 2011. [Internet] [acesso em 01 jul 2014]: Disponível: http://www.esenf.pt/fotos/editor2/ saude_e_qualidade_de_vida_uma_meta_a_atingir.pdf

12. Vieira EM, Perdona GSC, Santos MA. Factors associated with intimate partner physical violence among health service users. Rev. Saúde Pública. [Internet]. 2011;45(4) [acesso em 03 jul 2014]: Disponível: http://dx.doi. org/10.1590/S0034-89102011005000034

13. Ministério da Saúde (BR). Atenção integral para mulheres e adolescentes em situação de violência 
doméstica e sexual. Ministério da Saúde [Internet]. Brasília, 2011 [acesso em 01 jul 2014]: Disponível: http://bvsms.saude.gov.br/bvs/publicacoes/atencao_ integral_mulheres_violencia_domestica.pdf

14. Urquia ML, O'Campo PJ, Heaman MI, Janssen PA, Thiessen KR. Experiences of violence before and during pregnancy and adverse pregnancy outcomes: An analysis of the Canadian Maternity Experiences Survey. BMC Pregnancy and Childbirth. [Internet] 2011;11(42) [acesso em 25 jan 2014]. Disponível: http:// www.biomedcentral.com/1471-2393/11/42

15. Trigueiro TH, Labronici LM. Chemical Dependency as a risk factor for domestic violence against women: an exploratory study. Online Braz J Nurs. [Internet] 2011;10(2) [acesso em 25 jan 2014]. Disponível: http:// www.objnursing.uff.br/index.php/nursing/article/ view/3266

16. Ferraz MIR, Lacerda MR, Labronici LM, Maftum MA, Raimondo ML. O cuidado de enfermagem a vítimas de violência doméstica. Cogitare enferm. [Internet] 2009;14(4) [acesso em 25 jan 2014]. Disponível: http://ojs.c3sl.ufpr.br/ojs/index.php/cogitare/article/ view/16395/10874 